\title{
Aplicación del método Matte como estrategia para el fortalecimiento del proceso lector en el grado primero en una institución educativa
}

\section{Application of the Matte method as a strategy for strengthening reading processes in the first degree in an educational institution}

\author{
Nury Rocío Gómez Barahona \\ Especialista en Orientación Vocacional y Ocupacional \\ Magíster en Educación (c) \\ Correo electrónico:ngomez233@unab.edu.co \\ Universidad Autónoma de Bucaramanga, Bucaramanga, Colombia \\ Manuel José Acebedo Afanador \\ Doctor en Educación \\ Correo electrónico: macebedo@unab.edu.co \\ Universidad Autónoma de Bucaramanga, Bucaramanga, Colombia
}

Recibido: 27 de abril de 2017. Aprobado 28 de mayo de 2017

\section{Cómo citar este artículo:}

Gómez, N.R., y Acebedo, M.J. (2017). Aplicación del método Matte como estrategia para el fortalecimiento del proceso lector en el grado primero de una institución educativa. Espiral, Revista de Docencia e Investigación, 7(2), 53 - 74.

\section{Resumen}

Objetivo. El presente artículo de investigación se propone aplicar el método Matte para el aprendizaje de la lectura y la escritura, como estrategia para el fortalecimiento de estas competencias en los estudiantes que inician el ciclo escolar. Partiendo de los postulados de Emilia Ferreiro sobre el aprendizaje de la lectoescritura y los aportes de Claudio Matte creador del método, se procuró reorientar el proceso alfabetizador hacia la superación de la tendencia mecanicista, a partir del diseño de una propuesta contextualizada, que requirió del ajuste de estrategias y recursos pedagógicos necesarios para su implementación.

Metodología. La investigación se llevó a cabo con estudiantes del grado primero en una institución educativa oficial, bajo la metodología de investigación acción, organizada en cuatro fases. La contextualización en la que se adelantaron tareas de caracterización de actores, la implementación en la que se realizaron acciones de diseño, adaptación y aplicación de las estrategias y recursos para el aprendizaje, además de la orientación a padres de familia, las cuales fueron armonizadas con requerimientos normativos e institucionales.
Resultados y conclusión. La fase de reflexión permitió el registro de información pertinente, para la retroalimentación en los diarios pedagógicos, y la fase de valoración fue desarrollada transversalmente con una implicación "atemporal". La efectividad del método se demuestra en bajos niveles de desaprobación del año escolar y en los aportes identificados en cada categoría de análisis. Finalmente, entre las limitaciones se mencionan la falta de compromiso de algunos padres de familia, en el acompañamiento de las actividades complementarias de aprendizaje y en la formación de hábitos adecuados.

Palabras clave: Aprendizaje significativo, escritura, estrategia pedagógica, lectura, recurso didáctico.

\section{Abstract}

Textual and objective typology. This research article aims to present the application of the Matte method for learning to read and write, as a strategy to strengthen these competences in students who start the school year. Based on the postulates of Emilia Ferreiro on the learning of literacy and the contributions 
of Claudio Matte creator of the method, we tried to reorient the literacy process to overcome the mechanistic tendency, with the design of a contextualized proposal, which required the adjustment of strategies and pedagogical resources necessary for its implementation.

Methodology. The research was conducted with first grade students in an official educational institution, under the action research methodology, organized in four phases: the contextualization -in which actor characterization tasks were carried out-, the implementation -in which design, adaptation and application of strategies and resources for learning were carried out-, as well as guidance to parents, which were harmonized with regulatory and institutional requirements.

The reflection phase allowed the recording of pertinent information for feedback in the pedagogical journals and the assessment phase was developed transversally with a "timeless" implication.

Results and conclusion. The effectiveness of the method is demonstrated by low levels of failure at school and the contributions identified in each category of analysis. Finally, some limitations were found, such as the lack of commitment of some parents, in the accompaniment of complementary learning activities and in the formation of appropriate habits.

Keywords: Meaningful learning, writing, pedagogical strategy, reading, teaching resource.

\section{Introducción}

La presente investigación tuvo como propósito el diseño de una propuesta para el mejoramiento de las competencias lectoescritoras, mediante la aplicación del método Matte, en el grado primero de una institución educativa oficial. Desde esta perspectiva se inicia un acercamiento con el objeto de estudio, a partir de la contextualización del problema, como punto de partida en la determinación de las características del entorno y sus manifestaciones en los resultados en las pruebas de Estado. Estos insumos permiten el planteamiento de la pregunta de investigación como eje articulador para la formulación de los objetivos que direccionaron el estudio.

A partir del entramado teórico se hizo posible la comprensión del problema y la determinación de las acciones que en el diseño metodológico se encaminaron hacia la consecución de las metas planteadas. En este sentido, la investigación fue trabajada en cuatro fases. La primera fase o de contextualización, en la que se desarrollaron acciones encaminadas hacia la caracterización de los actores involucrados: estudiantes, padres de familia y educadores. Posteriormente, en la fase de implementación, se llevó a cabo la puesta en marcha de la propuesta, desde el momento de la planeación de la práctica pedagógica con todas sus implicaciones: adecuación del aula, gestión de planes de asignatura y de aula, diseño, selección de recursos para el aprendizaje y la evaluación, hasta las acciones de acompañamiento y orientación a padres de familia.

La tercera fase, dedicada a la reflexión, se efectuó a través del registro de los diarios pedagógicos, que en su estructura narrativa incluían un apartado dedicado al ejercicio reflexivo con el fin de recabar información que permitiera la retroalimentación permanente del proceso.

Finalmente, en la fase de valoración desarrollada de manera transversal, se presenta la valoración de avances y dificultades hallados durante la experiencia, en el marco de cada una de las categorías y subcategorías de análisis. Esta fase aportó la información necesaria, para la determinación de los resultados de la investigación y la formulación de las recomendaciones para la réplica de la propuesta en ocasiones futuras.

\section{Sobre el concepto de lenguaje}

Dado que el núcleo generador de aprendizaje, que convoca la presente investigación es el lenguaje en tanto su representación codificada, se hace imprescindible construir un marco que lo defina desde el imaginario científicamente aceptado. Retomando a Piaget (1970) quien indica que el lenguaje "es un sistema simbólico y, por tanto, arbitrario" (citado en Cano, 2006, párr. 24) lo que permite inferir que el desarrollo del lenguaje como herramienta para la comunicación requiere de la construcción previa de simbolizaciones que permitan el paso de lo 


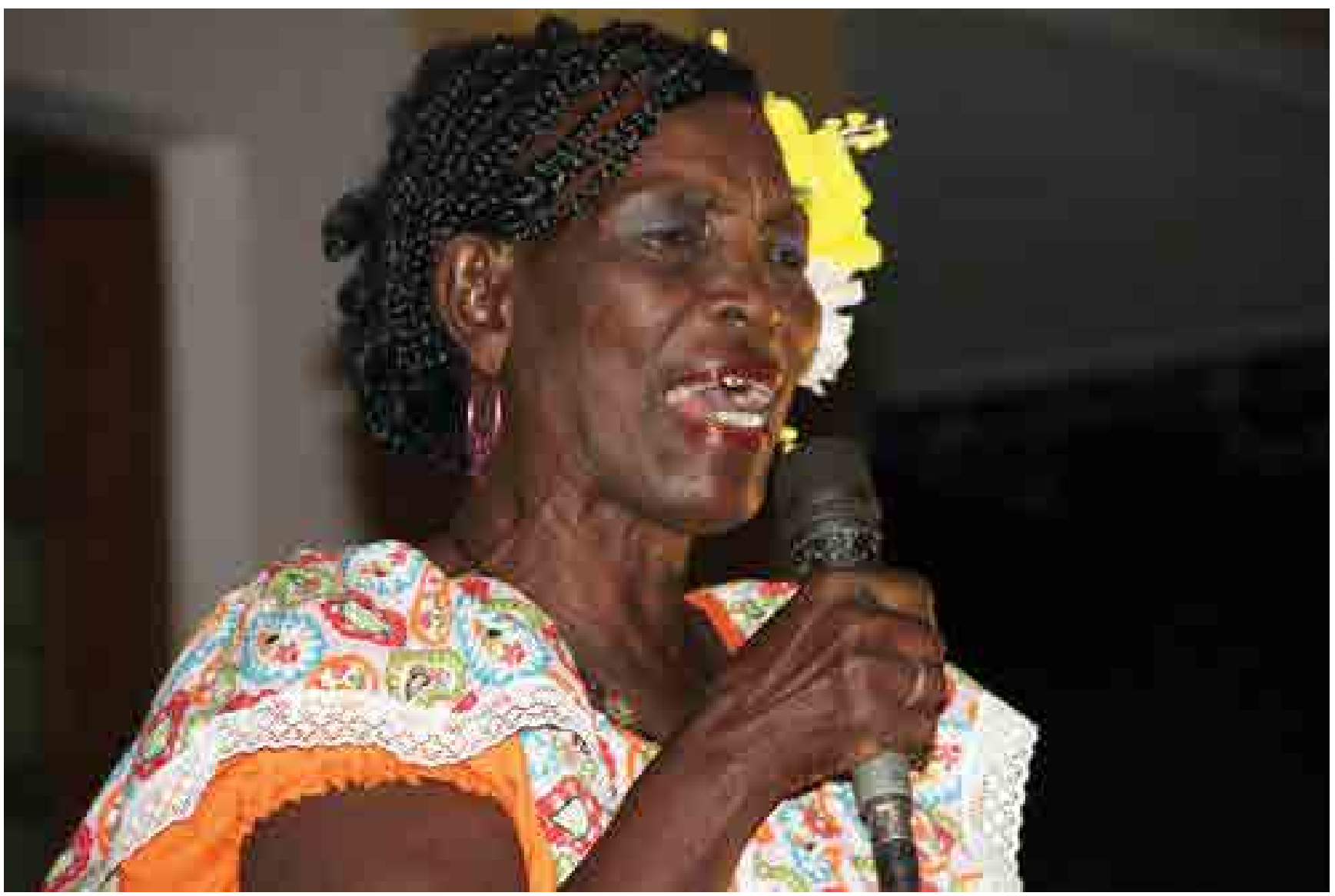

concreto a lo abstracto. Es así como los saberes que anteceden al aprendizaje de la lectura y de la escritura corresponden a los repertorios concretos construidos por el niño en su realidad social e inmediata.

Cuando el niño inicia su proceso de alfabetización es pertinencia de la escuela que esos aprendizajes se trasladen al plano de lo abstracto, a través de la codificación. Esta traducción de las experiencias al lenguaje escrito revela la indisoluble relación entre el lenguaje y el pensamiento, en el marco de un proceso progresivo, que tal y como lo plantea Piaget, en su teoría del desarrollo cognitivo, atraviesa por diversas instancias mediadas por la interacción del niño con el entorno físico y social.

Por su parte, según Ferrer (2005) el lenguaje se conceptualiza desde una perspectiva social en la que cumple una función conectiva entre las generaciones y los estamentos que confor- man una sociedad. Según esta autora el lenguaje se concibe como:

Un vehículo a través del cual se conoce el mundo. Como se ha visto, el lenguaje estructura la percepción de la realidad y da el significado a la experiencia. A través de él se identifican objetos e ideas y la expresión de pensamientos, permitiendo acumular grandes cantidades de conocimientos y transmitiendo cultura de una generación a otra. El lenguaje está en el corazón mismo de la cultura. Es uno de los vehículos cohesivos que acerca a las personas, mantiene unida la cultura y coordina los esfuerzos de los individuos en la sociedad (p. 171).

Esta visión del lenguaje reconoce su función como mediador entre el pensamiento y el mundo concreto, en una interacción permanente que al ser comunicada construye el entramado cultural de los colectivos humanos. Es de resaltar el valor que la autora le atribuye al lenguaje, como factor cohesivo entre las personas en el 
sentido de permitir el acuerdo, la participación, la proposición de nuevas ideas y el trabajo colaborativo para la consecución de fines comunes que impacten positivamente a los conglomerados sociales.

\section{La competencia comunicativa}

La competencia lingüística ha sido definida por Barón y Müller (2014) refiriéndose a la teoría de Noam Chomsky, de la siguiente manera:

La competencia corresponde a la capacidad que tiene un hablante-oyente idealizado para asociar sonidos y significados conforme a reglas inconscientes y automáticas. La actuación, o ejecución lingüística, corresponde a la interpretación y comprensión de oraciones de acuerdo con la competencia, pero regulándose además a partir de principios extralingüísticos, como las restricciones de la memoria, e incluso las creencias (p. 420).

En esta definición se aprecian dos conceptos que deben ser analizados de forma independiente, el primero se refiere a la competencia que se asigna a una persona, cuyas habilidades para expresar y asimilar contenidos lingüísticos se basan en un extenso repertorio de vocablos, cuyo significado y utilización contextual le permiten un manejo eficiente de la lengua, tanto en su expresión verbal como escrita. A este respecto se considera que Chomsky desconoce las particularidades que surgen en el camino que conlleva la construcción de las competencias relacionadas con el lenguaje; optando por una orientación basada en los resultados de un proceso, que bien podría construirse y enriquecerse a lo largo de toda la existencia.

Según los autores anteriormente citados, en la teoría de Chomsky la ejecución lingüística representa un proceso dependiente de la competencia, el cual cumple dos funciones diferenciadas: la interpretación y la comprensión de unidades estructurales del lenguaje, considerándolo desde una perspectiva reduccionista que fragmenta en oraciones el sentido de un texto como unidad de expresión lingüística y de pensamiento. Adicionalmente, para ellos Chomsky indica que algunos factores, como la capacidad para retener información en un lapso de tiempo determinado o las creencias sobre el contenido del objeto lingüístico, influyen en su ejecución, desconociendo la valía de los aportes que pueden ofrecer a la construcción de significados la experimentación, la sensopercepción, la indagación, entre otros.

Con el propósito de superar las limitaciones que presenta la consideración de una "competencia lingüística" surge entonces el concepto de "competencia comunicativa", que desde los postulados de Hymes (citado en Pilleux, 2001) se define como:

Un conjunto de habilidades y conocimientos que permiten que los hablantes de una comunidad lingüística puedan entenderse. En otras palabras, es nuestra capacidad de interpretar y usar apropiadamente el significado social de las variedades lingüísticas, desde cualquier circunstancia, en relación con las funciones y variedades de la lengua y con las suposiciones culturales en la situación de comunicación. Se refiere, en otros términos, al uso como sistema de las reglas de interacción social (párr. 7).

En esta definición, se procura una superación de las limitaciones presentadas por Chomsky al reducir sus consideraciones al plano de lo lingüístico, pero coinciden tomando como punto de partida la denominación de la competencia como una "capacidad". Hymes hace una extensión del concepto hacia todos los procesos involucrados en la comunicación como actividad cognitiva, social, cultural y generadora de significados. De la misma manera este autor reconoce la influencia del contexto en la consolidación de esta competencia y su carácter individual, al actuar como catalizador de motivaciones, necesidades y experiencias que a su vez actúan como elementos de entrada para mantener el flujo permanente del ciclo comunicacional. 


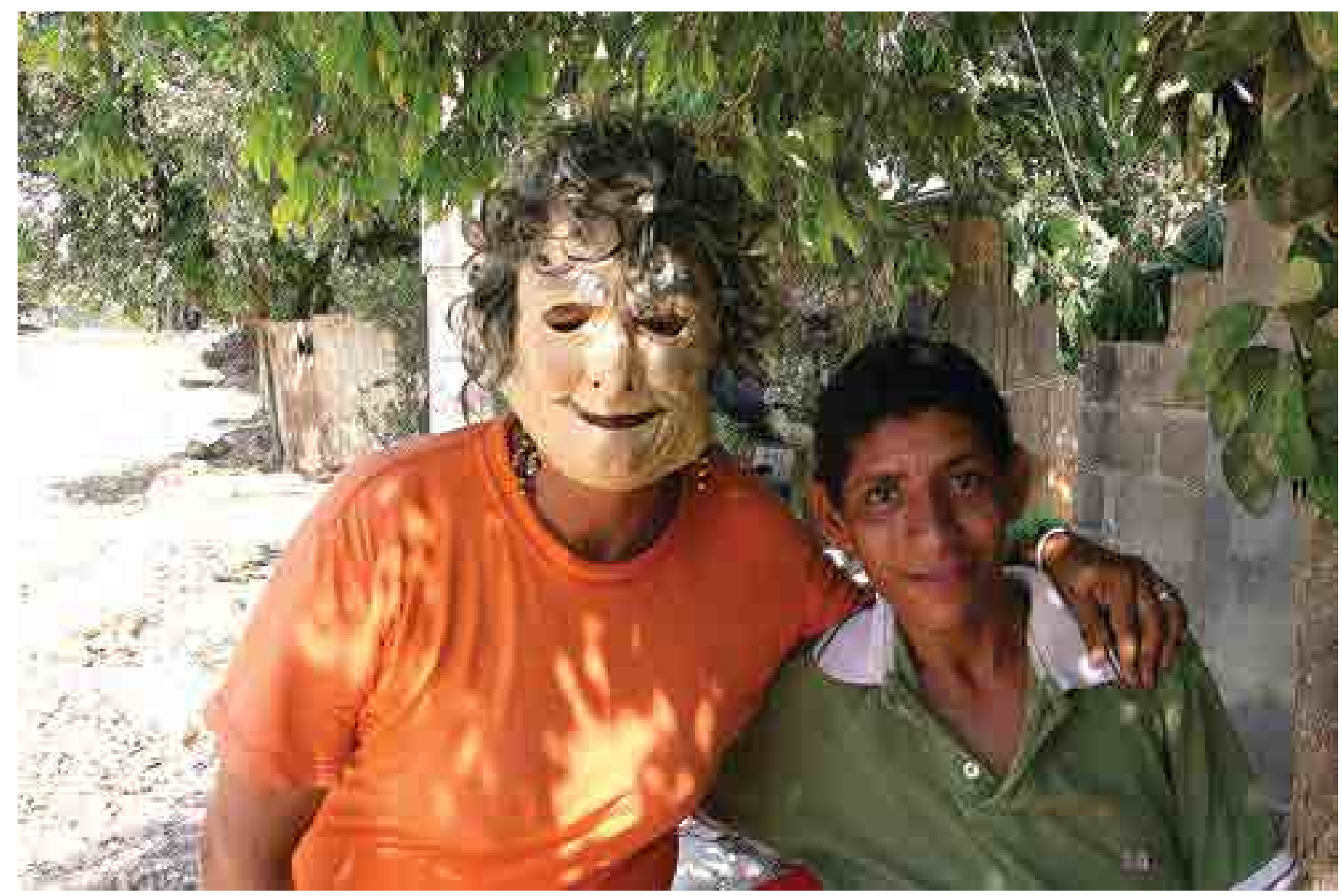

\section{El aprendizaje de la lectura y la escritura}

En la actualidad, el aprendizaje de la lectura y la escritura representa para el estudiante una "llave maestra" que asegura el acceso ilimitado a las fuentes de conocimiento disponibles no solo en el mundo físico, sino en el universo virtual. A este respecto Ferreiro (2001) refiere:

Desde sus orígenes, la enseñanza de estos saberes se planteó como la adquisición de una técnica: técnica del trazado de las letras, por un lado, y técnica de la correcta oralización del texto, por otra parte. Sólo después de haber dominado la técnica surgirían, como por arte de magia, la lectura expresiva (resultado de la comprensión) y la escritura eficaz (resultado de una técnica puesta al servicio de las intenciones del productor) (p. 2).

La autora presenta una visión histórica de la enseñanza de la lectoescritura, en la que estas competencias son abordadas como "técnicas" $y$ no como procesos. De esta manera la escritura es concebida como una habilidad puramente motriz, en la que se desconoce su función primordial como eje simbólico del pensamiento y de toda la actividad cognitiva del ser humano. Por su parte, la lectura, desde este planteamiento, surge inicialmente como una habilidad para decodificar un conjunto de símbolos, regidos por ciertas reglas que constituyen un código. La interacción comprensiva con el contenido de este código, se presume, debe surgir sin ningún tipo de mediación didáctica, de una forma natural cuando el niño supere las dificultades de la instancia anterior.

\section{Métodos para el aprendizaje de la lectura y la escritura}

El aprendizaje de la lectura y de la escritura, por tratarse de la competencia matriz sobre la cual se edifican los conocimientos interdisciplinarios a lo largo de la existencia, requiere entre 
otras condiciones de un método estructurado que direccione los elementos pedagógicos, organizativos, didácticos y humanos, en torno al propósito de acompañar al estudiante en la construcción de estrategias para interactuar con el lenguaje.

A pesar de la importancia del aprendizaje de la lectura y la escritura, la elección de un método para emprender este propósito representa a menudo un interrogante de difícil solución. A este respecto Mendoza, López \& Martos (1996 citados en Oporto, 2012) refieren:

La práctica docente permite observar que mediante procedimientos diferentes se pueden alcanzar distintos tipos de resultados y que ningún método de enseñanza puede tener una superioridad inherente que le permita alcanzar de forma plenamente satisfactoria todos los resultados que se pretenden (p. 14).

Bajo la óptica de estos autores, cualquier método que sea implementado para alcanzar un propósito de aprendizaje lleva implícitos componentes internos que se relacionan con la naturaleza del diseño en sí mismo; además de componentes externos provenientes del contexto donde es aplicado, los cuales representan debilidades y fortalezas potenciales para el proceso. Ante los planteamientos anteriores se reconocen ciertos factores, que habrán de ser tenidos en cuenta a la hora de asumir la selección de un método para la enseñanza de la lectura y la escritura. Entre estos factores es posible mencionar:

El conocimiento del método por parte del profesional de la educación, dado que su elección e implementación se encuentran sujetas al dominio de las bases teóricas que lo sustentan y a la comprensión plena de sus mecanismos de acción. De esta manera el método de enseñanza otorgará el sentido a las acciones emprendidas y justificará la disposición de prácticas pedagógicas y estrategias curriculares.
Las características del contexto, ya que ningún método debería ser llevado a la práctica desprovisto de la realidad que lo convoca. Desde este planteamiento, la institución educativa, la comunidad, la ciudad y la región constituyen núcleos de expectativas sobre los cuales el educador fijará pautas que orienten su elección.

Los actores implicados en el método, en este apartado se trata de considerar las particularidades de quienes aprenden con el método, pero también considerará los puntos de vista de padres o cuidadores, quienes deberán asumir un rol activo en el proceso desde los entornos familiares.

La disponibilidad de recursos para la implementación del método, ya que de una u otra manera se hará necesaria la dotación de algunos elementos que favorezcan su aplicación, representando con ello una inversión para el educador, para la institución educativa y en algunos casos para los padres de familia.

\section{Método Matte para la enseñanza de la lectura y la escritura}

Este método fue creado en 1884 por Claudio Matte, profesor y rector de la Universidad de Chile, con base en su visita a varias escuelas de educación primaria en Alemania. Matte había observado que en su país natal se empleaba para la enseñanza de la lectura y la escritura el método del Silabario, el cual era definido en sus palabras como "fastidioso y lento". Después de recabar información entre profesores, el autor se convence de las ventajas del método, que también era aplicado en aquella época en países como Austria y Suiza. De esta manera se propone, con su propio respaldo financiero, ajustar el método original a las particularidades del idioma español.

El método Matte puede ser considerado como mixto, ya que, desde el paradigma sintético, aborda la enseñanza de las estructuras que componen una unidad de sentido lingüístico, desde su totalidad abarcando sus elementos 


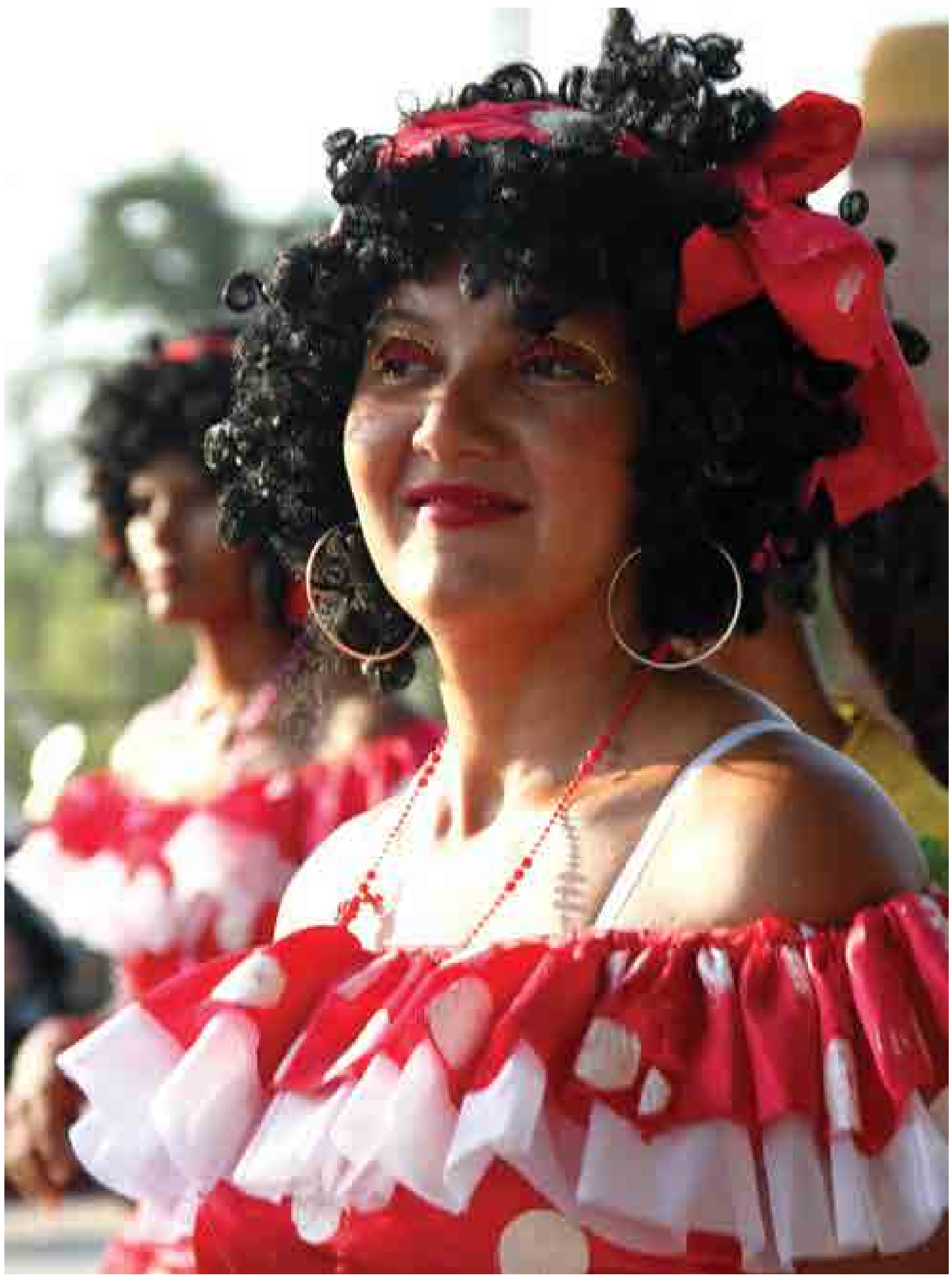


constitutivos; es decir, desde las palabras, para ir a las sílabas y culminando en los fonemas, en un proceso de doble sentido que en primera instancia descompone la unidad, para luego recomponerla. Este planteamiento se basa en el aprovechamiento de la curiosidad natural que despierta un nuevo objeto en los niños.

Es así como las palabras generadoras representan un nuevo objeto de conocimiento que debe ser "desarmado" y "armado nuevamente, para reconocer su funcionamiento. Por esta razón en este método se pospone la enseñanza de los nombres de los fonemas, ya que, en el proceso de lectura, estos prácticamente se "desechan" al ser combinados en la formación de sílabas y palabras. De esta manera, a partir de cada palabra generadora, los niños reconocen los fonemas en su pronunciación y representación simbólica independiente, para luego incorporarlos en estructuras más complejas hasta llegar a las palabras y oraciones.

El método Matte (1884) reúne de igual manera elementos pertenecientes al paradigma analítico, ya que el proceso de descomposición y recomposición de las palabras exige del análisis de cada unidad estructural en forma aislada y como parte de un todo provisto de sentido. Se hace imprescindible destacar, que el autor propone la generación de significados tal y como se expresa a continuación:

Por esto se toman vocablos que representen cosas familiares a los niños $y$, en lo posible, capaces de excitar su curiosidad. Estas cosas sirven de tema para lecciones de objetos, con auxilio de las cuales se aviva el interés del niño por la enseñanza y se desarrollan sus facultades. Si la palabra representa, p. ej., un animal, se mostrará a los alumnos un ejemplar natural o figurado de él y se les exhortará a discurrir y hacer observaciones acerca de su color, de su tamaño, de sus formas, del fin de sus diversas partes, de su utilidad, de sus costumbres, entre otras. En fin, se tratará por todos los medios posibles de llamar la atención del niño a la palabra respectiva, antes de proceder a desarrollar los sonidos que la componen (p. 6).

\section{Recursos para la enseñanza de la lectura y la escritura}

En armonía con los planteamientos de Ballesta (1995) quien define los materiales empleados en la enseñanza de la siguiente manera:

Son todos aquellos instrumentos y medios que proveen al educador de pautas y criterios para la toma de decisiones tanto en la planificación como en la intervención directa del proceso de enseñanza-aprendizaje. No cabe duda que la elección y utilización de los materiales de enseñanza representan decisiones básicas para lograr la coherencia de la actuación docente. Son herramientas que, en manos del docente se convierten en mediadores del aprendizaje del alumnado (p. 5).

Se hace imprescindible puntualizar acerca de la importancia que reviste la selección, ajuste y diseño de los recursos para el aprendizaje en el caso de la enseñanza de los procesos de lectura y escritura. A este respecto se observa que con alguna frecuencia los educadores soportan la aplicación de un método para este propósito, en el uso de textos y cartillas comerciales, los cuales demarcan el recorrido pedagógico de estudiantes y docentes en el camino de la alfabetización. Esta opción valorada a simple vista bien podría representar un desahogo para el profesional de la educación, al no obligarse al diseño de materiales para acompañar su quehacer diario, pero también pueden significar serias limitaciones al momento de superar las necesidades individuales, las características del contexto y el nivel socioeconómico de los grupos familiares.

Frente a esta realidad el educador podría pensar en el ajuste, diseño o selección de recursos que promuevan el aprendizaje significativo de sus estudiantes, para lo cual se deberán considerar algunos criterios tal y como lo afirma Bravo (2004):

En la selección y posterior utilización de medios didácticos intervienen una serie de factores, muchos de ellos ajenos a los propios medios, 
como son la disponibilidad de estos y otros que dependen tanto de los alumnos como del lugar donde vamos a impartir la docencia y, en este último caso, de las condiciones ambientales en las que la clase se desarrolla (p. 118).

En este sentido el método Matte, por tratarse de una metodología basada en la actividad cognitiva del estudiante, debe integrar recursos que aseguren la motivación, el interés, la variedad y la correlación de los contenidos de aprendizaje, en una unidad dinámica que reúna las características esenciales del método, las particularidades de la población objeto y la disponibilidad de los materiales en función del propósito de aprendizaje.

\section{El rol del educador en la enseñanza de los procesos de lectura y escritura}

Tan importante como el método para la enseñanza, los recursos didácticos y la motivación para aprender de cada estudiante, es la función del educador, no solo en el sentido estricto de su desempeño profesional sino en su interacción humana. Barbosa (1999) refiere que "el docente debe reunir un conjunto de condiciones, producto de su formación en el ser, en el saber y en el hacer" (p. 3). Siguiendo este planteamiento el autor señala los diferentes roles que el educador debe asumir: Como investigador, al indagar sobre las preferencias, expectativas, necesidades y presaberes de los estudiantes. Como observador, al permanecer atento a todas las manifestaciones de los niños sin intervenir en su libre desarrollo social. Como organizador, al asumir la responsabilidad como gestor, administrador y orientador de todos los componentes que intervienen en el proceso de aprendizaje.

Según Barbosa, además de las anteriores funciones, un educador deberá ser un informador, disponible para dar cuenta del estado de avance del proceso a los interesados, ya sean padres de familia, autoridades administrativas e incluso al mismo estudiante, generando en todo momento espacios comunicativos efec- tivos, respetuosos y éticos en los que ofrecerá sus apreciaciones, pero también escuchará las observaciones e inquietudes de la comunidad educativa. Este ejercicio recíproco facilita la oportunidad para que el maestro sea un aprendiz, que aprovechará al máximo su experiencia pedagógica, para reinventarse y transformar su quehacer, enriqueciéndolo teóricamente y buscando nuevas opciones para facilitar los aprendizajes. Finalmente, este autor señala que el papel del maestro involucra también una función como evaluador, en la que ofrece una mirada justa, desprovista de sesgos emocionales, mediante la descripción cualitativa del progreso de cada educando y el análisis situado de las dificultades.

\section{El papel de la familia en el aprendizaje de la lectura y la escritura}

La familia es el primer escenario en el que los niños construyen los repertorios iniciales, que posteriormente serán la base que fundamente todo el recorrido educativo que transitará a lo largo de la existencia. Cuando el niño asiste a la institución educativa esos límites se amplían y emerge para él un nuevo mundo material, social y cultural en el que debe desenvolverse sin la presencia de sus padres o cuidadores. De esta dinámica surgen interacciones entre los actores educativos y los grupos familiares, hasta ahora autónomos en la formación de los hijos, para procurar el logro de los propósitos establecidos. Al respecto de la relación padre de familia y educador, Domínguez (2010) refiere:

Esta relación se convierte hoy en día en un pilar muy fuerte para la eficacia y respuestas positivas del desarrollo educativo y personal de los alumnos/as. Se ha demostrado que en caso de no existir esta cooperación el niño/a tendrá muchos problemas en su evolución escolar y se producirán muchas limitaciones y por el contrario si se da esta cooperación adecuada, el alumno/a evolucionará satisfactoriamente y son muchos las ventajas de las que disfrutará el niño/a (p. 1).

Ante este planteamiento, la institución educativa debe extender su acción formativa hacia 
los grupos familiares, en el sentido de brindar orientaciones pertinentes que permitan un adecuado acompañamiento desde el hogar. En la realidad colombiana se presentan variados factores que limitan esta función: el nivel educativo de los padres, la falta de tiempo disponible del padre por razones laborales, la poca disponibilidad de recursos para el aprendizaje, los patrones inapropiados de crianza, la diversificación en la estructura familiar, los patrones culturales arraigados sobre la responsabilidad exclusiva de la escuela en el proceso educativo, entre otros.

Por esta razón se hace necesario implicar a las familias, dotarlas de las herramientas necesarias para que desde el hogar mantengan una unidad de criterio con la institución escolar. De la misma manera, se requiere del fortalecimiento de los canales y las oportunidades de comunicación, bajo una perspectiva de corresponsabilidad en la que se acuerden y se concreten acciones que busquen continuamente el mejoramiento de los aprendizajes y de los ambientes en los que los estudiantes conviven.

\section{El desarrollo humano y la alfabetización}

En la actualidad, el uso de la lectura y la escritura se encuentra fuertemente enraizado en la cotidianidad de los seres humanos. Es el pase de entrada al mundo de la sociedad de la información en la que el conocimiento ya no es posesión de unos pocos, sino un patrimonio global disponible a solo un clic de distancia. La Organización de las Naciones Unidas para la Educación, la Ciencia y la Cultura (2008) al respecto de la alfabetización refiere:

Nunca antes había sido más necesaria para el desarrollo, dado que es vital para todo tipo de comunicaciones y aprendizajes y una condición sin la cual no es posible tener acceso a la actual sociedad del conocimiento. Ante la profundización de las brechas socioeconómicas y las crisis mundiales del agua, el alimento y la energía, la alfabetización representa un instrumento de supervivencia en un mundo altamente competiti- vo. La alfabetización lleva al potenciamiento en tanto que el derecho a la educación incluye el derecho a ser alfabetizado, un requisito fundamental para el aprendizaje a lo largo de toda la vida y un vehículo esencial para el desarrollo humano y alcanzar los objetivos de desarrollo del milenio (ODM) (p. 9).

De esta manera el aprendizaje de la lectura y la escritura representa un factor de empoderamiento personal en la medida en que promueve el aprendizaje autónomo, la independencia en las actividades de la vida diaria, el acceso a la información y las producciones científicas, artísticas y culturales y en prospectiva es el punto de partida que permite avanzar en una formación vocacional que se traduce en empleo y en el consecuente mejoramiento de la calidad de vida.

\section{Metodología}

La investigación se realizó bajo un enfoque cualitativo de tipo investigación-acción. Pérez y Nieto (1992) indican respecto a la investigación en educación:

Investigar en educación supone la búsqueda de estrategias de cambio para lograr el perfeccionamiento; investigar sobre la praxis implica siempre mejorar la realidad concreta sobre la que se opera. El investigador en la acción siempre desea aportar algo nuevo a la educación, a la enseñanza o a la rama del saber que cultiva (p. 180).

En relación con la investigación-acción, Elliot (1990) refiere:

Al explicar lo que sucede, la investigación-acción construye un "guion" sobre el hecho en cuestión, relacionándolo con un contexto de contingencias mutuamente interdependientes, o sea, hechos que se agrupan porque la ocurrencia de uno depende de la aparición de los demás (p. 5).

En el contexto del presente estudio, este guion al que hace referencia el autor, constituye la carta de navegación sobre la cual se orientó el rumbo de las tareas investigativas, permitiendo el registro sistemático de la experiencia desde la óptica de todos los actores convocados. La 


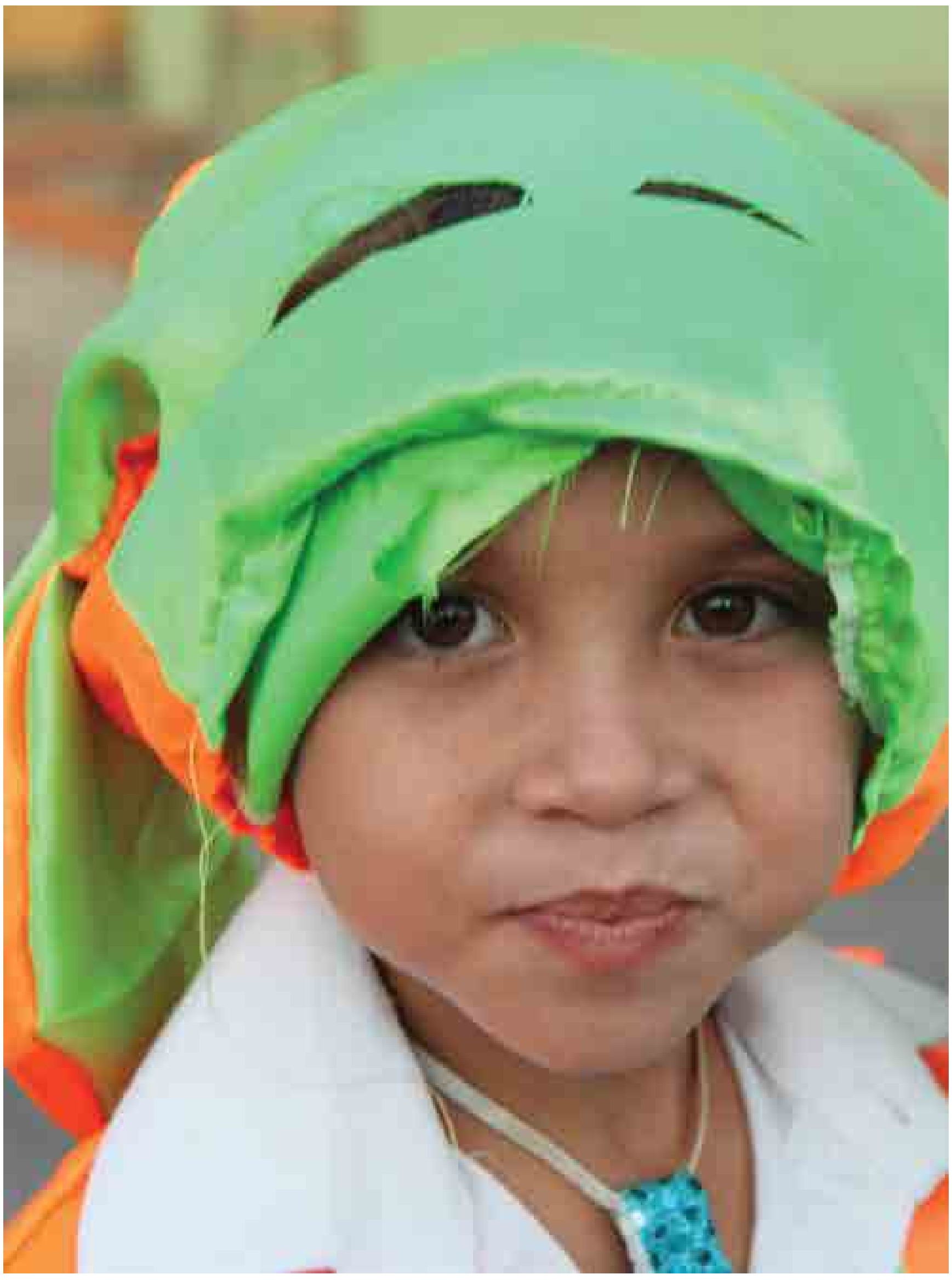


población objeto estuvo representada por 78 estudiantes del grado primero de educación básica primaria, en una institución oficial, de los cuáles se tomó una muestra de 42 estudiantes correspondientes a una de las jornadas escolares.

El proceso de recolección de información se hizo con base en cuatro instrumentos: una entrevista semiestructurada, el registro de los diarios pedagógicos, la revisión documental y la observación participante. Desde esta perspectiva se aplicaron entrevistas semiestructuradas a los educadores que se desempeñaron en el grado primero en el ciclo de educación básica primaria en los últimos 10 años, con el fin de recabar información pertinente acerca de los métodos implementados, para la enseñanza de los procesos de lectura y escritura y a su vez obtener datos relacionados con las dificultades observadas por los profesionales en estos procesos, en los grados posteriores a la alfabetización.

En cuanto a los diarios pedagógicos tal y como lo indica Martínez (2007) refiriéndose a los diarios de campo "es uno de los instrumentos que día a día nos permite sistematizar nuestras prácticas investigativas; además, nos permite mejorarlas, enriquecerlas y transformarlas" (p. 77). A este respecto el diario pedagógico se registró de acuerdo con la pertinencia, la relevancia y el aporte de las experiencias a la consecución de los objetivos propuestos en la investigación. Previamente a la aplicación del método se hizo necesario solicitar ante el consejo académico de la entidad, la autorización para efectuar un ajuste al plan de asignatura del área de lengua castellana del grado primero, con el fin de favorecer el desarrollo del presente estudio, sin afectar el uso de otras metodologías de enseñanza, empleadas por otros educadores.

El proceso de aplicación del método Matte fue registrado de forma sistemática, en sus aspectos pedagógicos en los planes de aula del área de lengua castellana, en los cuatro perio- dos que componen el año escolar, empleando los formatos de registro que se proponen a nivel institucional dentro del sistema de gestión de calidad.

Por su parte, en cuanto a la revisión documental, de acuerdo con Sampieri, Hernández \& Baptista (2000) consiste en "detectar, obtener y consultar la bibliografía y otros materiales que parten de otros conocimientos y/o informaciones recogidas moderadamente de cualquier realidad, de manera selectiva, de modo que puedan ser útiles para los propósitos del estudio" (p. 50). Entre los documentos que fueron objeto de revisión documental en el presente estudio se encuentran: El proyecto educativo institucional, los planes de área y asignatura de lengua castellana del grado primero, los planes de aula de lengua castellana.

En cuanto a la observación participante, se aplicó de manera permanente durante la implementación del proyecto y los resultados de la misma enriquecieron los diarios pedagógicos, las entrevistas a los educadores y los hallazgos obtenidos durante la revisión documental, en el sentido de permitir el establecimiento de conexiones entre los entornos teóricos y contextuales. Con respecto a este tipo de observación, Sampieri et al. (2000) refieren:

El investigador entra en el campo a examinar con un abierto propósito de exploración. Esta técnica representa un papel real, pues el investigador se ve como un miembro del grupo a pesar de no estar completamente integrado dentro de los objetivos y actividades del grupo. El relacionarse con determinadas personas del grupo permite al investigador ganar la confianza necesaria y mostrar varios puntos de vista (p. 6).

Desde el planteamiento de estos autores, la observación participante permite obtener información in situ sin recurrir a los relatos anecdóticos de los protagonistas de los fenómenos y situaciones observables. En el marco de este proyecto, esta técnica de recolección de datos se empleó, mediada por las intenciones plan- 
teadas en los objetivos, con lo cual se direccionaron los espacios, situaciones, personas y momentos susceptibles de ser observados.

Para dar cumplimiento a los objetivos propuestos en el estudio, se implementaron cuatro fases:

Fase de contextualización en la que se llevaron a cabo las tareas de caracterización de los participantes involucrados en la investigación: estudiantes, padres de familia y educadores.

Fase de implementación durante la cual se realizaron las planeaciones de aula reflejando la aplicación del método, se diseñaron las adaptaciones al contexto en cuanto a los sus diferentes componentes: contenidos, los recursos y apoyos didácticos como guías de aprendizaje, selección y recopilación de material multimedia, adecuación del aula. De la misma manera en esta fase se propusieron los ajustes que se consideraron necesarios en los planes de área y asignatura con el propósito de armonizar las particularidades del método, con la plataforma curricular existente en la institución, en el marco del sistema de gestión de calidad.

En este momento del proceso de la investigación se abrieron espacios dedicados a los padres de familia, por medio de los cuales se procuró su sensibilización respecto al método y el favorecimiento en el manejo de las estrategias desde los hogares, así como la dinámica escolar que implicaba la puesta en marcha del proyecto.

Fase de reflexión la cual se llevó a cabo a través del registro de los diarios de campo, que en su estructura narrativa incluían un apartado dedicado al ejercicio reflexivo. En este espacio fueron consignados los aportes obtenidos a partir de la experiencia vivida durante la aplicación del método y permitieron la recolección de información vital para retroalimentar y dirigir constantemente el proceso. Las reflexiones fueron expresadas de manera muy concisa a través de frases y afirmaciones puntuales, con el fin de generar impacto en los interesados en futuras aplicaciones del método. En este propósito los diarios de campo también incluyen unas recomendaciones derivadas del presente estudio, que facilitarían la implementación de las estrategias en próximas ocasiones.

Fase de valoración que fue desarrollada de manera transversal con una implicación "atemporal" dentro del proceso, ya que, en el curso de la investigación, no se prevé un momento específico para la valoración de avances y dificultades. Esta tarea será llevada a cabo a lo largo de todo el estudio y ofrecerá la información necesaria para la retroalimentación y realización de ajustes.

\section{Análisis de resultados}

Bajo la premisa de obtener información pertinente que contribuyera con el logro de los propósitos de la investigación, se identificaron cuatro categorías que orientaron las acciones de diseño y aplicación de los instrumentos de recolección de la información, al igual que su posterior organización y análisis.

La primera categoría se relaciona con el proceso de lectura, entendido como la habilidad para establecer una relación con el texto en la que el lector no solo reconoce las reglas que rigen el código comunicativo, ya sea visual, escrito u oral, sino que además construye un significado que le permite modificar sus estructuras cognitivas. La segunda categoría corresponde al proceso de escritura, entendido como la producción de textos empleando un código escrito. En el grado primero la producción textual se asume desde la dinámica de traducir el texto oral a signos gráficos o escritura y desde la producción espontánea y autónoma de textos muy sencillos compuestos por una o más oraciones.

La tercera categoría reúne el diseño, búsqueda, selección, aplicación, contextualización y ajuste de los recursos didácticos necesarios en la implementación de un método 


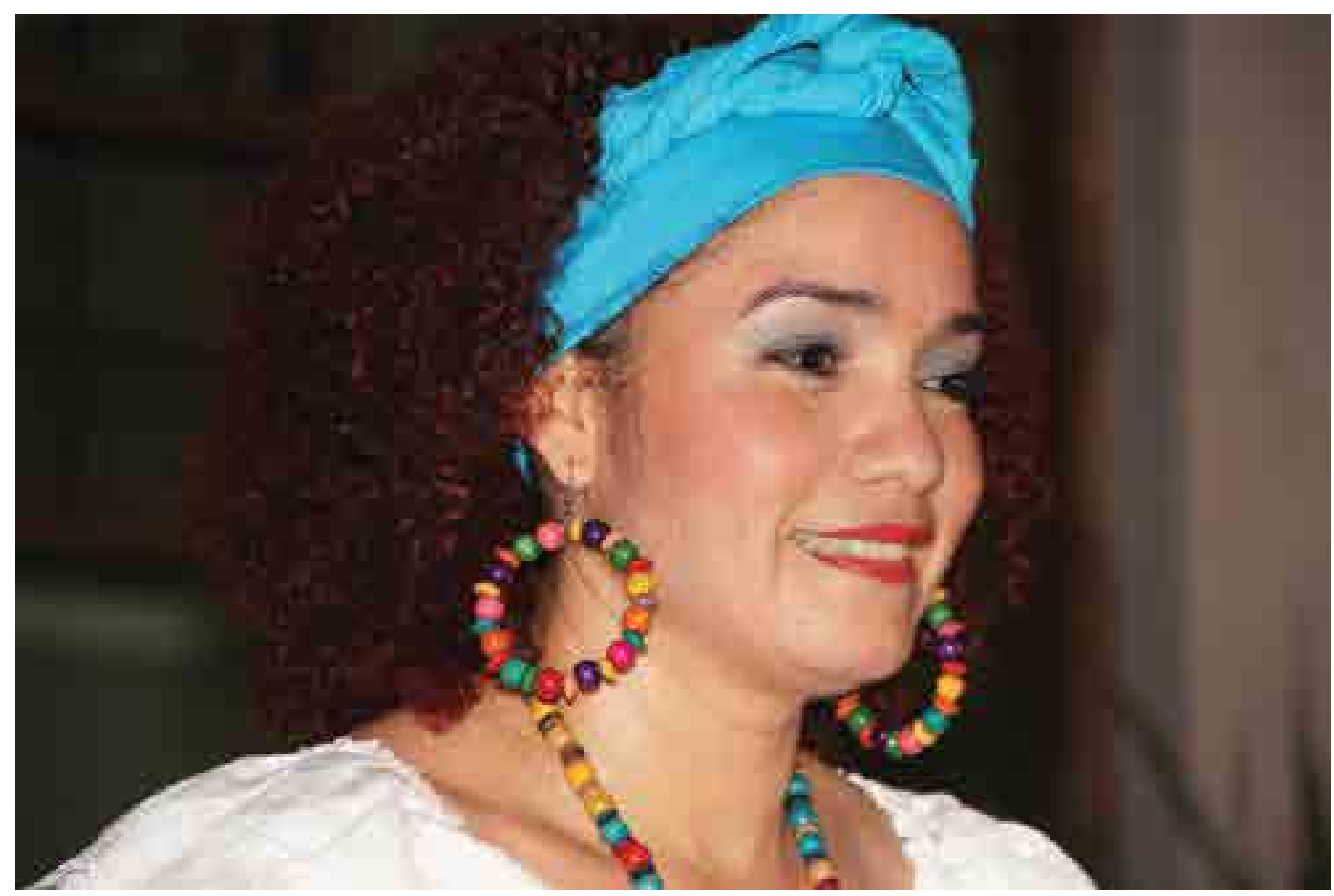

para la enseñanza de la lectura y la escritura. Estos recursos pueden ser impresos (guías de aprendizaje, afiches, carteles), audiovisuales y tecnológicos, entre otros. Y finalmente, la cuarta categoría que reúne la intención de formar seres humanos que desde el inicio de su proceso educativo reconozcan los valores de convivencia en sociedad y con el entorno natural. En este sentido se reconoce la importancia del "saber ser" como parte fundamental de cualquier aprendizaje.

En la fase de contextualización se halló que la totalidad de muestra provenía del sector urbano, y que con frecuencia la ubicación distante de sus viviendas interfería con el proceso, ya que debido a las impuntualidades se ocasionaba la pérdida del espacio pedagógico. En cuanto al nivel sociocultural se estableció que la mayoría de los estudiantes provienen de hogares identificados como vulnerables. En lo relacionado con el nivel académico se halló que en el grupo de aplicación se presentaban casos de repitencia escolar y presencia de casos de estudiantes en situación de discapacidad cognitiva y necesidades educativas especiales.

En los resultados de la entrevista aplicada a los educadores de básica primaria, se indagó a los educadores acerca de su conocimiento sobre el método implementado en la institución, para la enseñanza de los procesos de lectura y escritura, reconociendo que entre estos se encuentran: el método GEEMPA y el de las palabras normales. Todos coinciden en afirmar que la selección del método en la entidad, durante algún periodo de tiempo, se basó en una exigencia del Ministerio de Educación Nacional. Sin embargo se confirma, que a pesar de los esfuerzos emprendidos en materia de capacitación de docentes, dotación de recursos para el aprendizaje, mobiliario y equipos tecnológicos por parte de este organismo administrativo, cuando los educadores capacitados abandonan 
la institución, ya sea por solicitud de traslado o pensión obligatoria, estas iniciativas pierden su continuidad.

Por su parte algunos de los docentes indicaron, que la selección del método para la enseñanza de la lectura y la escritura queda a cargo del titular del grado, con base en criterios de experiencia previa en su utilización, conocimiento del mismo por parte del profesional y el uso de los recursos disponibles como cartillas y textos comerciales.

Con respecto a la aplicación del método GEEMPA, se observa una tendencia marcada a señalar aspectos deficitarios ocasionados con su aplicación entre las que se destacan: desconocimiento de las letras minúsculas por parte de los niños, dificultad para el reconocimiento y uso de los signos de puntuación, ejecución caligráfica deficiente en cuanto la precisión del trazo y la legibilidad, dificultades en la comprensión y la producción de textos escritos. Así mismo, se expresa como falencia el hecho de capacitar un solo docente para la implementación del método, ya que ante eventuales situaciones como las mencionadas en apartados anteriores, todos los esfuerzos emprendidos por la entidad administrativa se consideran ineficaces.

En relación con el uso del método de las palabras normales, los docentes mencionan el uso de las planas como estrategia para el aprendizaje de la escritura, la inclusión de imágenes que se asocian con la lectura y el dictado como forma de seguimiento a los avances dentro del proceso.

Es de resaltar que ninguno de los docentes entrevistados se refiere a los métodos desde su perspectiva conceptual y se remiten solamente a aspectos relacionados con su implementación didáctica en términos de los materiales, la identificación de las unidades de contenido (palabras, sílabas, letras, oraciones) y el orden en la disposición de los mismos, pro- curando una estructura deductiva en el pensamiento de los estudiantes.

Cuando se les preguntó a los entrevistados sobre la principal dificultad que presentan los estudiantes de básica primaria en el área del lenguaje, los docentes identifican la comprensión lectora, como una de las principales dificultades observadas en los estudiantes en el área del lenguaje durante el ciclo de primaria. Según su testimonio los niños no dan cuenta de lo que leen, se muestran más preocupados por el desciframiento mecánico del código escrito, que por aproximarse al contenido que este expone. De la misma manera, estos profesionales indican que los hábitos lectores de sus estudiantes son precarios en cuanto a la periodicidad con la que leen y a los materiales de lectura, que en su mayoría se reducen a los contenidos que circulan en redes sociales y comunicaciones informales.

Para los entrevistados, el método debe considerar los procesos de pensamiento de los niños, en tanto que debe inducirlos a la resolución de problemas, a la expresión de sus experiencias y a la búsqueda pertinente de información. De la misma manera, consideran importante el desarrollo de habilidades como la transcripción de textos, la toma de dictados, el reconocimiento y uso adecuado de los signos de puntuación, la progresiva fluidez en la lectura y la legibilidad en los trazos. Desde la perspectiva del maestro, los entrevistados consideran que el perfil del docente alfabetizador en el grado primero debe reunir varias cualidades entre las que mencionaron: la paciencia, la creatividad, el dominio de las TIC, la ética y la dedicación. De esta manera le otorgan al maestro una amplia responsabilidad en el éxito de este proceso.

Según la información aportada los docentes confirman el papel fundamental que desempeñan los padres de familia, en la obtención de óptimos resultados en el aprendizaje de la lectura y la escritura. A este respecto los maestros consideran que de manera eventual los padres 
dejan recaer en la institución la responsabilidad del proceso formativo de los niños, excluyéndose por razones laborales y educativas, por lo que evidencian la necesidad de extender la labor de la institución hasta los grupos familiares, para orientarlos en la implementación de estrategias de acompañamiento de las actividades complementarias. De esta manera, los entrevistados reconocen que el ambiente en el hogar ejerce influencia en el desempeño académico de los niños, en aspectos como el buen trato, la aplicación de patrones adecuados de crianza, el fomento de hábitos de lectura y la formación en valores.

En cuanto a las características que debería tener un método adecuado para la enseñanza de la lectura y la escritura, los educadores entrevistados expresaron diversas condiciones que según su criterio debe reunir un método. Estas características fueron analizadas y agrupadas en 3 categorías: las características relacionadas con el enfoque, las relacionadas con los recursos didácticos y las relacionadas con el rol del educador para su implementación. Dentro de la categoría de las características desde el punto de vista del enfoque, los entrevistados mencionaron que debe ser activo, lúdico, partir de lo fácil e ir complejizándose progresivamente, debe ser organizado y secuencial, considerar unidades globales de pensamiento (palabras y no sílabas), iniciar el dominio ortográfico y la comprensión de texto y, por último, algunos educadores coinciden en que debe ser contextual en el sentido de retomar contenidos propios del entorno del estudiante.

Desde el punto de vista de los recursos didácticos, informan que un método apropiado para la alfabetización en el primer grado debe emplear recursos lúdicos, llamativos, incluir imágenes y en lo posible involucrar los recursos provenientes de las TIC. Desde el punto de vista del rol del educador en la implementación del método, se encuentra que los profesionales mencionaron cualidades como la creatividad, el dinamismo, la paciencia, el dominio de estra- tegias didácticas motivantes, variadas y la disposición para establecer una relación positiva con sus estudiantes.

\section{Aplicación del método Matte para el aprendizaje de la lectura y la escritura}

La aplicación del método tal y como se muestra en la figura 1, exige el seguimiento riguroso de una serie de pasos que conforman la ruta didáctica en el aprendizaje de cada una de las palabras generadoras. Cada lección corresponde a una palabra generadora que a su vez enseña cada una de las letras y dígrafos del alfabeto. Al finalizar esta secuencia se inicia la enseñanza de las combinaciones consonánticas con ly r.

\section{Actividades iniciales o de motivación}

Este paso constituye el encuentro inicial del niño con la palabra generadora. Por esta razón se hace imprescindible que este momento represente una experiencia motivadora, que logre captar la atención y el interés del estudiante. Al efectuar la selección de estrategias y recursos para su abordaje, el educador debe tener en cuenta la edad de los niños, sus intereses, la relación del recurso con la palabra y la posibilidad de tomarlo como punto de partida para la estimulación de las diferentes inteligencias. Una vez efectuada la actividad inicial, el educador debe retomarla como referente para establecer un conversatorio que explore los presaberes del grupo. La pregunta es el medio más eficaz para cumplir con este propósito y para llevar a los niños hacia el contacto con otras disciplinas del conocimiento, reforzando y ampliando conceptos, experiencias, observaciones, entre otros. En la aplicación del método se tuvieron en cuenta diferentes recursos TIC y estrategias lúdicas.

\section{Presentación de la palabra generadora}

En la experiencia de aplicación del método desarrollada en esta investigación se diseñaron presentaciones en el programa Power Point, con el propósito de favorecer el interés de los 


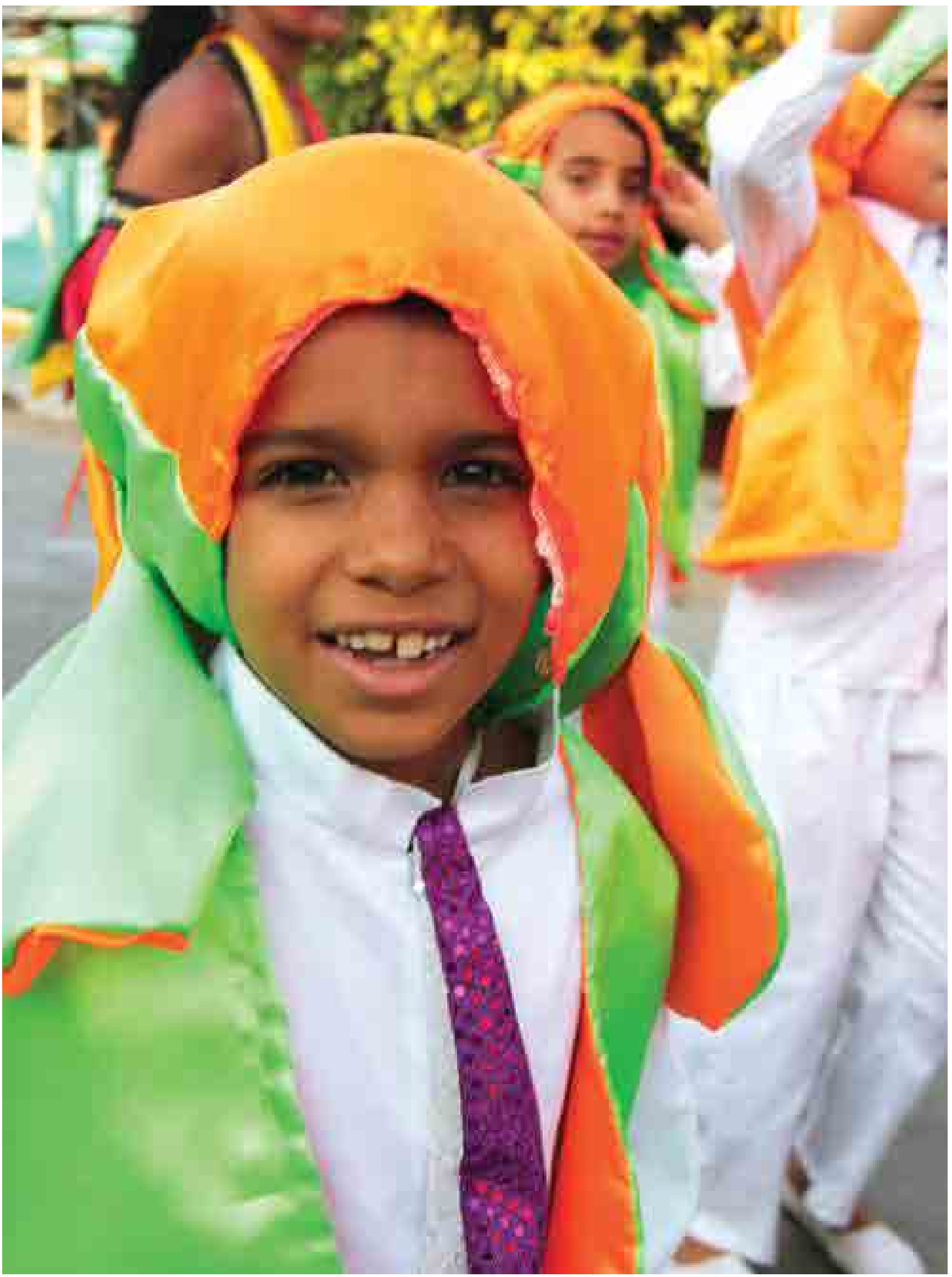


estudiantes y generar una herramienta perdurable, pertinente, dinámica y de fácil ajuste para aplicaciones posteriores. Cada lección contó con una presentación en la que se presentaba la palabra como una unidad gramatical acompañada de un gif o imagen llamativa para los niños. Posteriormente al dar clic la palabra iba descomponiéndose en sus elementos estructurales: sílabas, fonemas.

El educador acompaña el proceso de análisis efectuando la pronunciación clara de cada unidad y permitiendo que el grupo la repita. Luego se abre paso a los ejercicios individuales de pronunciación, siempre acompañados del apoyo simbólico de la presentación. El análisis de las palabras generadoras se acompañó de diversas estrategias para desarrollar la conciencia fonológica, como: dar un golpe de tambor en cada unidad sonora, dar un paso en cada unidad, hacer una palma, dar un saltito, entre otros. En la síntesis de la palabra, esta se re-construye nuevamente. Aquí el educador puede sugerir anticipaciones al proceso preguntando ¿Qué letra sigue?, ¿qué ocurre si sigue esta letra?, ¿cuántas letras faltan para completar la palabra?

\section{Escritura de la palabra generadora}

Realizado el análisis fonológico de la palabra generadora, los niños pasan al plano escrito a partir de una guía de aprendizaje. Durante el primero y segundo periodo del año escolar las guías de aprendizaje se diseñaron teniendo en cuenta el manejo del espacio gráfico, tal y como se presentaba en las diapositivas. De esta manera los niños encontraban cuadros en la disposición de cada etapa del análisis de la palabra en particular, separados de acuerdo con el número de sílabas y grafías en los que debían escribir los componentes de la palabra analizada.

La fuente seleccionada para el diseño de las guías es Comic Sans MS, debido a que en esta fuente en particular, las letras "a" en minúscula se componen de un círculo y una línea vertical, mientras que en otras fuentes esta letra presen- ta un trazo diferente. Adicionalmente, los niños debían efectuar un dibujo relacionado con la palabra generadora como estrategia para consolidar la simbolización de la realidad y favorecer la expresión artística. Teniendo en cuenta que en el modelo pedagógico de la institución se contempla el desarrollo de las inteligencias múltiples, las guías fueron diseñadas en papel tamaño oficio en orientación horizontal, ubicando la guía en duplicado de manera que de una hoja pudiesen obtenerse dos guías que al separarse ocuparan el mismo espacio que una página del cuaderno de cada niño. Este diseño evita el desperdicio de papel y contribuye con el desarrollo de la inteligencia naturalista y la conciencia de cuidado del medio ambiente. Culminado el primer semestre las guías de aprendizaje fueron ajustadas debido a la necesidad de que los niños recibieran entrenamiento en el manejo del renglón, por ello se prescindió de los cuadros y se sustituyó el espacio de escritura por renglones.

\section{Lectura oral de la palabra generadora y generación de nuevas palabras}

Una vez se culmina el análisis y síntesis de la palabra generadora, el educador orienta su lectura a través de diferentes modalidades: lectura modelo, lectura individual silenciosa y en voz alta, lectura grupal en voz alta. Posteriormente, el educador invita a sus estudiantes a observar en la presentación de diapositivas otras palabras que inicien con la misma letra de la palabra generadora. Estas palabras son observadas por los estudiantes, al igual que el gif o imagen que la representa, su análisis y síntesis que siempre será reforzado mediante el modelado fonético por parte del educador. De igual manera, se introduce el concepto de número de sílabas de una palabra y si se considera pertinente su clasificación atendiendo este criterio. Este paso del proceso puede ser desarrollado en el contexto de un juego de atención, de competencia, de imitación, a través de acertijos, cumplimiento de retos o cualquier otra estrategia que el maestro considere pertinente. 


\section{Lectura y escritura en la guía de aprendizaje}

En este paso del proceso los niños llevan al plano escrito en la guía de aprendizaje las nuevas palabras descubiertas a partir de la palabra generadora y hacen el análisis y síntesis de cada una de ellas. Inicialmente, al recibir la guía cada uno realiza una lectura individual, siguiendo el modelado que ofrece el maestro, luego se efectúa la lectura en voz alta con la participación de algunos integrantes del grado. Finalmente se efectúa la lectura grupal en voz alta. Durante la escritura el educador debe efectuar un recorrido permanente por el aula para ofrecer el acompañamiento individual para asegurar la ejecución correcta de trazos y el uso adecuado del espacio gráfico y de ser necesario intervenir en las correcciones.

\section{Escritura de oraciones}

En cuanto a la escritura de oraciones, en las guías de aprendizaje se empleó la fuente penmanship con base en dos criterios: el demarcado del renglón diferenciando mayúsculas de minúsculas y la ejecución de trazos en letra script. Los niños en este paso hacen la lectura de las oraciones inicialmente en voz alta con participación designada por el educador quien posteriormente efectúa el modelado. Luego se hace la lectura silenciosa individual y finalmente la lectura grupal en voz alta. Finalmente, los niños realizan la escritura de las oraciones en su guía de trabajo.

\section{Evaluación}

La verificación del aprendizaje se realiza de manera permanente y en forma transversal a lo largo de la aplicación de los seis pasos anteriormente descritos. Sin embargo, al finalizar cada una de las lecciones, al día siguiente se hace un dictado de control en el que los niños deberán escribir sin apoyo gráfico las palabras vistas. Todas las lecciones incluyen un compromiso o actividad complementaria para ser desarrollada en el hogar. Los padres de familia fueron informados desde el inicio del proceso acerca de esta estrategia, por lo que estos saberes se acompañan y se refuerzan desde el contexto familiar. De la misma manera, las evaluaciones de la asignatura procuraron la verificación de la conciencia fonológica y de la construcción de significados por parte de los estudiantes.

\section{Conclusiones}

La aplicación del método Matte permitió una aportación al fortalecimiento de los procesos de aprendizaje de la lectura y la escritura, en los estudiantes del grado primero de educación básica de la institución educativa, representada en aspectos como el manejo adecuado del código lecto-escrito de acuerdo con sus niveles particulares de desarrollo, la producción de textos sencillos prescindiendo del apoyo de imágenes, la formación en valores ciudadanos y de convivencia, el incremento del repertorio léxico, la conexión entre los presaberes y los centros de interés como fundamento para la construcción de significados y la integración de los grupos familiares a las tareas de aprendizaje, a través de un acompañamiento asertivo, orientado desde el contexto escolar.

De esta manera, desde la aplicación del método Matte se logró generar una propuesta pedagógica que inicia con la adecuación del espacio físico, para continuar impactando aspectos inherentes a la estructura del servicio educativo. En esta perspectiva se efectuaron ajustes a los planes de asignatura armonizando las características del método, con los derechos básicos de aprendizaje, sin afectar la aplicación de otras metodologías empleadas por los educadores de la institución. Así mismo, los planes de aula reflejaron la puesta en marcha de la propuesta, constituyendo no solo una bitácora de la experiencia, sino generando un documento de apoyo para futuras aplicaciones.

La contextualización del método Matte se hizo posible mediante la modificación de algunas de las palabras generadoras que representaran mayor significación y relación del 


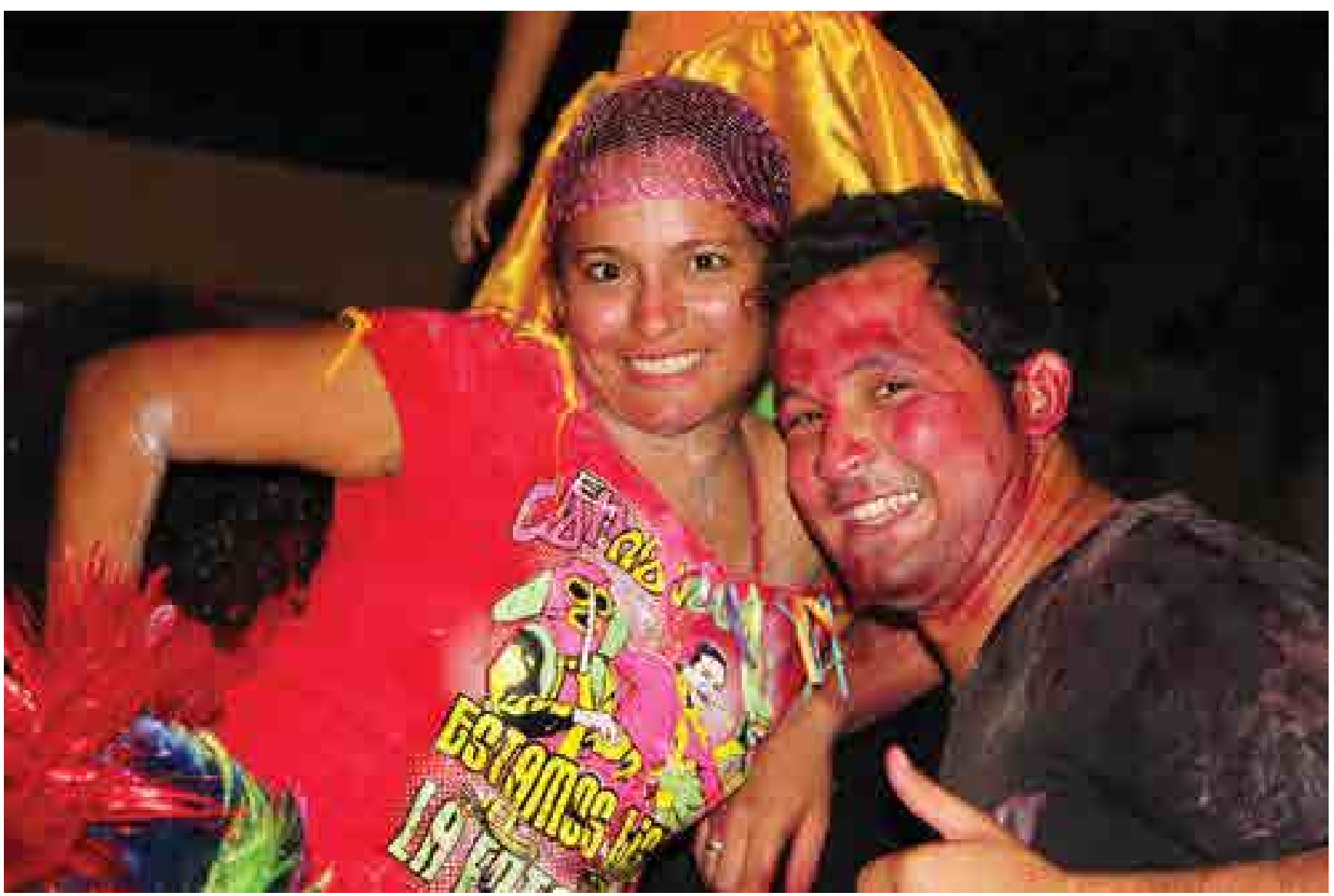

estudiante con su entorno. Por su parte, la incorporación de recursos para el aprendizaje que retomaran el uso de las TIC representó un acierto en la fase de implementación, ya que favoreció aspectos como el interés, la motivación, el incremento de los índices atencionales y la aprehensión de las rutinas didácticas por parte de los estudiantes.

El diseño de las guías, evaluaciones y presentaciones que acompañaron a cada una de las lecciones que componen la propuesta, fue otro de los aspectos destacados en el presente trabajo, no solo por su valor como producto derivado del mismo, sino porque facilitarán su posterior aplicación, simplificando para el educador las tareas de planeación, control y ejecución del método a lo largo del año escolar. A este respecto vale la pena destacar, que para el padre de familia este diseño de recursos propios para la enseñanza evita la inversión monetaria en la compra de textos comerciales, cartillas y materiales didácticos adicionales.

En cuanto a la efectividad del método Matte, se confirma que en términos de aportes al fortalecimiento de los procesos de lectura y escritura de los estudiantes del grado primero, el $95.2 \%$ de los estudiantes fueron promovidos al grado segundo. Solo el $4.8 \%$ representado en dos estudiantes, debieron reiniciar el grado, debido a la inconsistencia en el avance de los aprendizajes, ocasionada por la presencia de dificultades en al ámbito cognitivo y de salud. Entre los aportes logrados a partir de la aplicación del método, sobresalen el reconocimiento y aplicación de las reglas de desciframiento del código a través de la lectura con progresiva fluidez, la producción de textos escritos en diversas situaciones comunicativas sin apoyo de referentes visuales, la formación en valores de convivencia social lograda a través de las estrategias de intervención pedagógica y la cohe- 
sión alcanzada entre familia-colegio para lograr las metas propuestas.

En términos de dificultades, el presente estudio debió superar las limitantes ocasionadas por la falta de una actitud comprometida, por parte de algunos padres de familia en el acompañamiento de los niños en las actividades complementarias de aprendizaje, el establecimiento de hábitos de estudio y la modificación de patrones inadecuados de crianza.

Finalmente, los hallazgos y productos derivados del presente estudio sirvieron de insumo para la construcción de una propuesta institucional, generada a través del colectivo de investigación, con el propósito de hacer extensivas las estrategias para el mejoramiento de la competencia lectora en toda la población escolar.

La aplicación del método Matte para la enseñanza de la lectura y la escritura, representa una estrategia integral, que no solo se ocupa del aprendizaje de las reglas de desciframiento de un código comunicativo para leer y escribir, sino que retoma la concepción del estudiante desde todas sus dimensiones de desarrollo. En este sentido se hace necesario que, quien emprenda la ruta para su implementación integre a la rutina actividades lúdicas, recursos multimedia, espacios para la creación, la expresión artística y el trabajo colaborativo, desde la lectura situada de la realidad.

La contextualización del método constituye una instancia obligada en su aplicación, dado que los ejes temáticos para el caso de un método de alfabetización se encuentran sustentados en las palabras y oraciones como unidades básicas de sentido. De esta manera, estas unidades en lo posible deben surgir del entorno inmediato del estudiante para favorecer la utilización didáctica de sus presaberes y lograr con ello la identificación de los elementos de entrada que actuarán como insumos, para el diseño, adecuación y proposición de nuevas estrategias de intervención pedagógica.
El diseño, selección e integración de recursos para el aprendizaje debe seguir en lo posible tres condiciones básicas: pertinencia, accesibilidad y potencial de motivación e interés para los estudiantes. La pertinencia se refiere a la relación que guarda el recurso con el propósito o la intención didáctica, la accesibilidad establece la posibilidad de utilización del recurso en el contexto de aplicación y el potencial de motivación es la potencia estimada del recurso para despertar y mantener la capacidad de atención del estudiante.

La integración de los padres y núcleos familiares en la aplicación del método constituye una fortaleza, ya que desde este escenario es posible complementar, ampliar y fortalecer los aprendizajes iniciados en el ámbito escolar. De igual manera, es allí en donde los niños construyen hábitos de lectura y de estudio que se perpetúan a lo largo del trayecto de formación educativa.

\section{Referencias}

Ballesta, J. (1995). Función didáctica de los materiales curriculares. Pixel-Bit Revista de Medios y Educación, (5), 29-46. Recuperado de https://idus.us.es/xmlui/ handle/11441/45440

Barbosa, F. (1999). Incidencia del docente en la lectura y la escritura. Revista Educere, 3(5), 1-6. Recuperado de http:// media.utp.edu.co/referencias-bibliograficas/uploads/ referencias/articulo/131-incidencia-del-docente-en-lalectura-y-la-escriturapdf-rgqOD-articulo.pdf

Barón, L., Müller, O. (2014). La teoría lingüística de Noam Chomsky: del inicio a la actualidad. Recuperado de http:// www.scielo.org.co/pdf/leng/v42n2/v42n2a08.pdf

Pilleux, M. (2001). Competencia comunicativa y análisis del discurso. Estudios Filológicos, (36), 143-152. https:// dx.doi.org/10.4067/S0071-17132001003600010

Bravo, J. (2004). Los medios de enseñanza: clasificación, selección y aplicación. Pixel-Bit. Revista de Medios y Educación, (24). 113-124. Recuperado de http://acdc.sav.us.es/ ojs/index.php/pixelbit/article/view/827/760

Cano, A. (2006). Comunicación y lenguaje. Universidad de Castilla-La Mancha, España. Recuperado de https:// www.uclm.es/profesorado/agcano/comunicacion.htm

Domínguez, S. (2010). La educación, cosa de dos: La escuela y la familia. Revista temas para la Educación, (8), 1-15. Recuperado de https://educrea.cl/wp-content/ uploads/2017/03/DOC2-esc-y-fam.pdf

Elliot, J. (1990). La investigación acción en educación. Ediciones Morata, S.L. Recuperado de http://www.terras.edu. ar/biblioteca/37/37ELLIOT-Jhon-Cap-1-y-5.pdf 
Ferreiro, E. (2001). Pasado y presente de los verbos leer y escribir. Recuperado de https://books.google.com.co/bo oks? id=SgjGDQAAQBAJ\&pg $=$ PT25\&lpg $=$ PT25\&dq $=10$ $\mathrm{s}+\mathrm{ni} \% \mathrm{C} 3 \% \mathrm{~B} 1$ os+todos+los+ni\%C3\%B1os+se+los+as eguro+estan+dispuestos+a+la+aventura+del+apren dizaje\&source=bl\&ots $=$ YWs0RrHV6i\&sig=F1pSAZEDy 4x4yhp4hblu4cz0Ho\&hl=es-419\&sa =X\&ved=0ahUK EwjUwt3EmPDTAhVHKyYKHQJOBroQ6AEIJTAA\#v=on epage \&q=los\%20ni\%C3\%B10s\%20todos\%20los\%20 ni\%C3\%B1 os\%20se\%20los\%20aseguro\%20estan\%20 dispuestos $\% 20$ a $\% 201$ a $\% 20$ aventura $\% 20$ del $\% 20$ aprendizaje\&f=false

Ferrer, G. (2005). Del limbo a un proceso en el lenguaje. Cuadernos de Lingüística Hispánica, (7), 165-174. Recuperado de http://www.redalyc.org/pdf/3222/322230192015. pdf

Martínez, L. (2007). La observación y el diario de campo en la definición de un tema de investigación. Recuperado de http://datateca.unad.edu.co/contenidos/401121/diario_de_campo.pdf

Matte, C. (1884). Nuevo silabario del método Matte. Recuperado de https://issuu.com/conypradenas/docs/ metodo-matte
Oporto, S. (2012). Estudio sobre la posible influencia de las actividades extraescolares en la adquisición de la lectoescritura. (Tesis magistral). Universidad Internacional de La Rioja, España. Recuperado de http://reunir.unir.net/ bitstream/handle/123456789/523/Oporto.SaraMaria. pdf?sequence $=1$

Organización de las Naciones Unidas para la Educación, la Ciencia y la Cultura (2008). El desafío de la alfabetización en el mundo. Sector de Educación de la UNESCO División de Coordinación de las Prioridades de las Naciones Unidas en Educación, Francia. Recuperado de http://unesdoc.unesco.org/images/0016/001631/163170s.pdf

Pérez, S., y Nieto, M. (1992). La investigación-acción en la educación formal y no formal. Recuperado de http://espacio.uned.es/fez/eserv/bibliuned:20405/investigacion_accion.pdf

Sampieri, R., Hernández, C. \& Baptista, P. (2000). Metodología de la investigación. Recuperado de http://es.slideshare.net/gerardosanchezpereyra/ roberto-hernndez-sampieri-metodologa-investigacin 